286 Tropelías. Revista de Teoría de la Literatura y Literatura Comparada, 29 (2018)

Cristino de Vera

\title{
TAZA BLANCA EN SILENCIO
}

Cristino de VERA

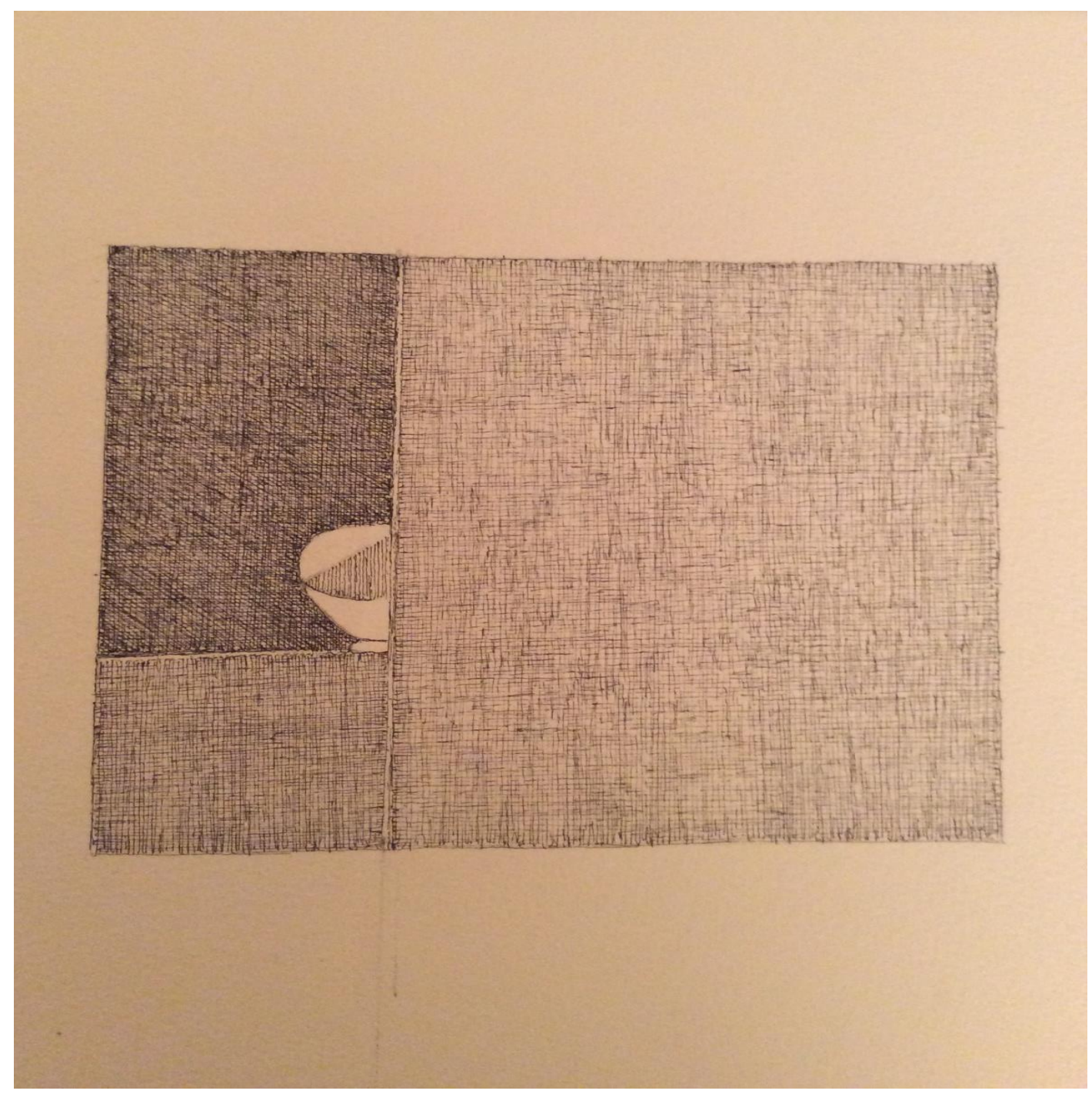

C2018 Cristino de Vera Todos los derechos reservados

TÍTULO: TAZA BLANCA EN SILENCIO TÉCNICA: TINTA CHINA SOBRE PAPEL FABRIANO

MEDIDAS: $32 \times 25$ 
A través de ese SILENCIO de la taza blanca que emanaba energía.

Pudo contemplar de la Cruz a La Luz, un alabastro de CHILLIDA volando en el espacio de la noche oscura.

Pudo contemplar un gigante caracol convertido en una ciudad.

A un hombre de espalda en un banco que se diluía y de frente era un Giacometti.

Contempló un rayo que gritaba en la oscuridad era el grito de Edvard Munch.

A través del SILENCIO que emanaba la TAZA, pudo contemplar el cambio de su rostro marcado por la amargura (a Marta Robayna)... ya en la divinidad.

Contempló una figura con un vestido de azul cielo llena de espíritu (Fra Angélico).

Contempló los más extraños, misteriosos y bellos ponientes y albas del mundo visible.

Contempló la variedad infinita de peces de los mares.

Contempló en la oscura noche del alma su propia alma, con giro de estrellas fugaces rayas de luz. Era un nuevo idioma que no comprendió.

Miró desde una ventana los colores, las flores, luces, riscos, montañas, volcanes (El Teide, El Fuji Japón) del mundo visible.

$\mathrm{Y}$

Comprendió con los dolores y sufrimientos que azotan a animales, insectos, especies y humanos.

Que el SILENCIO era el recinto que tanto buscó del «Plan Divino».

Y callado y en SILENCIO que salía de su templo interior musitó una ORACIÓN.

Y todo será como si nada hubiese sucedido. F. BRINES.

Con mi homenaje CALLADO

CRISTINO DE VERA

MADRID, FEBRERO 2017 